\title{
Surgical Correction of Trigonocephaly: Theoretical Basis and Operative Procedures
}

\author{
Eiji MORIYAMA, Hiroichi BeCK, Keiichi ISEDA, Nobuyuki SAITOH, \\ Masaru SAKURA * ${ }^{*}$, and Yuzo MATSUMOTO* \\ Department of Neurosurgery, Fukuyama National Hospital, Fukuyama, Hiroshima; \\ *Department of Neurosurgery, Kagawa Prefectural Central Hospital, Takamatsu
}

\begin{abstract}
Trigonocephaly involves premature fusion of both the metopic suture and the sutures in the skull base. Surgical treatment by opening of the prematurely fused metopic suture and expansion of the anterior cranial base by creating "neosutures" was used to treat three children with trigonocephaly. The combination of lateral canthal advancement and radical forehead remodeling achieved excellent results. These procedures can also prevent the development of midface hypoplasia such as hypotelorism. The two younger patients, aged 0 and 6 months, achieved rapid bone growth in the defects and normalization of intercanthal and interpupillary distances. The older patient, aged 8 years, retained some skull defects at follow-up. The optimal age for surgery is 3-6 months, which allows good cosmetic results and minimizes visual repercussions with relatively low perioperative risks.
\end{abstract}

Key words: craniosynostosis, metopic synostosis, trigonocephaly, lateral canthal advancement, radical forehead remodeling

\section{Introduction}

Trigonocephaly, the typical manifestation of metopic synostosis, is a relatively rare deformity of the skull characterized by triangular prominence of the forehead and orbital hypotelorism. ${ }^{4,5,14)}$ This condition is caused by premature closure of the metopic suture, which is normally patent until after 2 years of age. ${ }^{2,4,8,27)}$

Trigonocephaly usually occurs as the sporadic nonsyndromal type, which is associated with few, if any, abnormalities beyond those of the calvaria and orbits. In contrast, the syndromal type of trigonocephaly is associated with multiple congenital anomalies, most commonly epicanthal folds, cleft palate, and cardiac anomalies. ${ }^{5,7,10,19,22)}$ Forebrain dysplasia is also a major anomaly and full developmental assessment is therefore necessary before treatment. ${ }^{15,311}$

Metopic synostosis can be divided into three categories defined by the associated pathological elements: a) mild metopic synostosis manifested by a prominent midline forehead ridge without trigonocephaly or hypotelorism, b) metopic synosto-

Received June 6, 1997;

Accepted November 18, 1997 sis manifesting as trigonocephaly with deficient lateral supraorbital rims of normal bone thickness, and c) metopic synostosis manifesting as trigonocephaly with thick deficient supraorbital rims. $\left.{ }^{9}, 14\right)$

Flexible and individualized management of the metopic synostosis depends on the severity. ${ }^{9,14]}$ Patients with only a mild midline forehead ridge might be managed conservatively or need minor corrective surgery rather than complex procedures. More aggressive surgery is indicated for patients with severe deformities to aid in developing a normal skull contour.

We describe three patients with trigonocephaly, who successfully underwent surgical correction, and discuss the theoretical bases and technical aspects of modern surgical correction.

\section{Materials and Methods}

Three patients were treated in this series (Table 1). One neonatal female was not operated on because of severe cardiac anomaly and was excluded. Patients were classified according to the severity of deformity by the grading system defined by Delashaw et al. . $^{\text {) }}$

The typical appearance of trigonocephaly includ- 
Table 1 Summary of patients

\begin{tabular}{|c|c|c|c|c|c|c|}
\hline $\begin{array}{c}\text { Case } \\
\text { No. }\end{array}$ & Age & Sex & Severity* & Hypotelorism & $\begin{array}{l}\text { Follow-up period } \\
\text { (mos) }\end{array}$ & $\begin{array}{l}\text { Disappearance of skull defects } \\
\text { (mos) }\end{array}$ \\
\hline 1 & $0 \mathrm{mo}$ & M & C & severe & 18 & 18 \\
\hline $2^{\#}$ & $6 \mathrm{mos}$ & $\mathrm{M}$ & C & severe & 50 & 24 \\
\hline $3^{H}$ & 8 yrs & $\mathrm{M}$ & B & mild & 30 & - \\
\hline
\end{tabular}

*Severity of deformity was determined by the grading of Delashaw et al. ${ }^{9} \quad{ }^{*}$ Cases 2 and 3 are siblings.

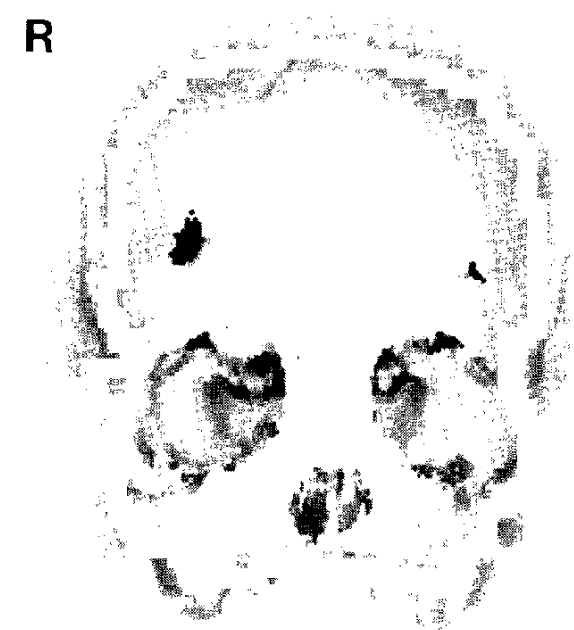

Fig. 1 Case 1. Preoperative three-dimensional osseous surface computed tomography scan, frontal view, showing the typical appearance of trigonocephaly including the wedgeshaped forehead, and ovoid and medially inclined orbits with hypotelorism.

ing the wedge-shaped forehead, and the ovoid and medially inclined orbit with hypotelorism are shown in the three-dimensional computed tomography (3DCT) of Case 1 (Fig. 1). Interpupillary and intercanthal distances of this patient were significantly reduced to below the 5th percentile of the normal distribution, 32 and $15 \mathrm{~mm}$, respectively. ${ }^{18)}$ Severe hypotelorism was also noted in Case 2.

Our operative procedures were the modifications of those reported by several authors. ${ }^{20-23,28]}$

Step 1: A bicoronal scalp incision is made, with the patient head in the supine position. The scalp flap is dissected in the subgaleal plane toward the supraorbital ridge. The pericranium is incised along a line parallel to the supraorbital rim and elevated together with the scalp flap down into the orbit, maintaining the transition between the intact perior- bita and the pericranium. Care must be taken not to damage the supraorbital nerves. The supraorbital foramina is opened whenever necessary.

The anterior part of the temporalis muscle is dissected to expose the pterional region. After placing burr holes as shown in Fig. 2A, bilateral coronal strip suturectomy is performed down to the sphenozygomatic suture. Then, triangular frontal craniotomies are made leaving the metopic suture as a bridge. Supraorbital osteotomy is carried out approximately $1 \mathrm{~cm}$ above the supraorbital rim. Finally, metopic suturectomy is performed (Fig. 2B).

Step 2: The frontal lobe is elevated extradurally to expose the floor of the anterior cranial fossa. Osteotomy is carried out with a high speed drill, through the floor just behind the supraorbital ridge, protecting the periorbita with a brain retractor in the orbit. The osteotomy is then continued laterally through the frontozygomatic process and medially just anterior to the crista galli. The pterion is rongeured off. This procedure is repeated on the contralateral side. This procedure frees the supraorbital bar except for the midline attachment to the nasion (Fig. 2C).

Step 3: The bilateral lateral canti are advanced and the supraorbital bar is straightened by a greenstick fracture on the midline (Fig. 2D). The new position of the superior orbital ridge is maintained by a buttress bone obtained from the calvaria and placed between the lateral canthus and the temporal border of the coronal craniectomy. Curved bone plates obtained from the coronal suturectomy are used to create the natural concave contour of the pterional region. Edges of the plate and the supraorbital ridge are planed at 45 degree to achieve better adaptation of the inner and outer tables as well as the diploic bone marrow (Fig. 2E). Axial CT is helpful to determine the extent of the advancement. ${ }^{28)}$ The buttress graft must be kept below the transition between the coronal (frontotemporal) and the sphenozygomatic (lateral orbital wall) sutures to prevent secondary coronal synostosis. ${ }^{23)}$ The frontonasal angle is normal in trigonocephaly and should be maintained during correction. ${ }^{28)}$ 

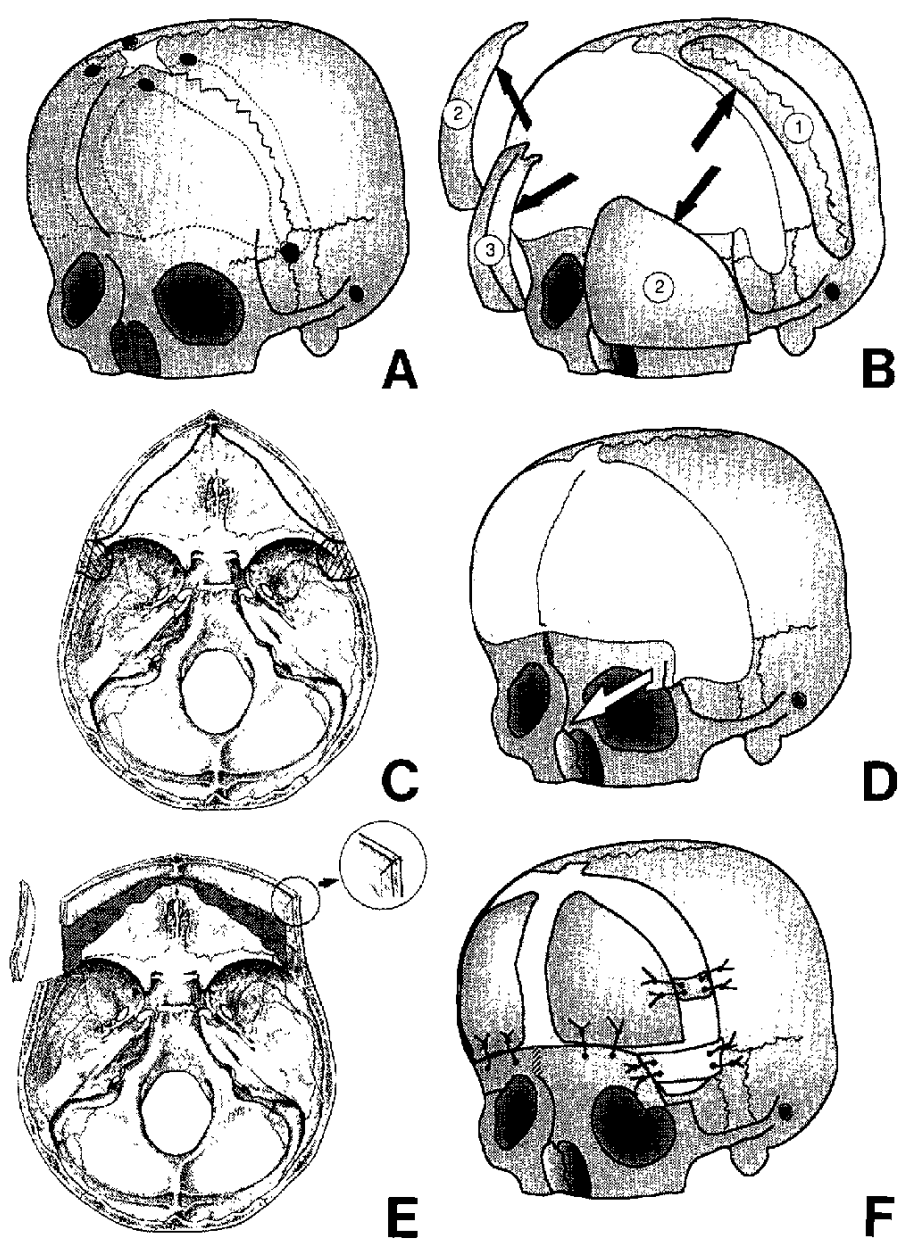

$\mathbf{F}$
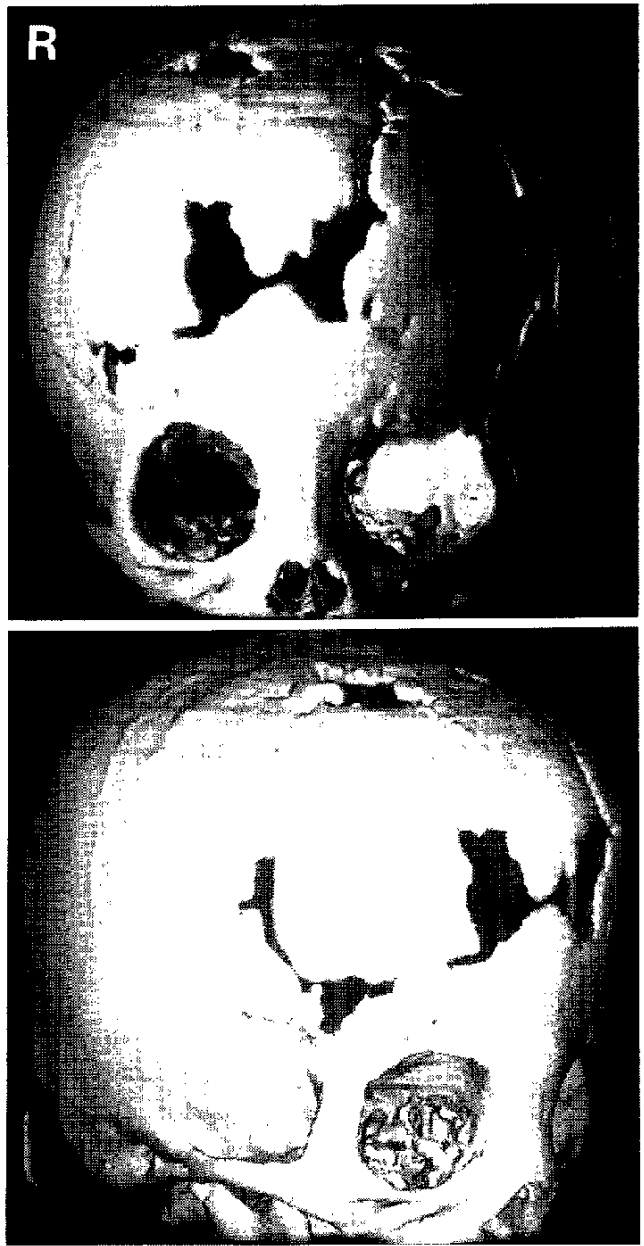

Fig. 3 Case 1. Postoperative three-dimensional osseous surface computed tomography scans 1 year after surgery, frontal (upper) and oblique (lower) views, showing the disappearance of the prominent frontal ridge, normal shape of the orbit, and normal appearance of the pterional region, with osteogenesis proceeding around the frontal flaps and the buttress bone grafts.

Step 4: The halves of the frontal flaps are approximated and sutured to the supraorbital bar. The best cosmetic shape possible should be achieved, which may require rotating the bone flaps. Another buttress graft can be placed between the frontal bone flap and the posterior frontal bone, but these should be left "floating" on the midline (Fig. 2F). A deficiency in the region of the pterion may also be present in metopic synostosis. The pterional region can be augmented by release of the temporalis muscle from the outer table and rotating forward to fill the concavity with remodeling of underlying bone..$^{9)}$ Finally, the wound is closed layer by layer leaving epidural 
drainage.

\section{Results}

No perioperative complications were observed. 3DCT of Case 1, 12 months after the surgery, showed the frontal ridge had disappeared and the shape of the orbits was normalized (Fig. 3). Postoperative expansion of the anterior cranial fossa was also clearly seen (Fig. 4). The interpupillary and intercanthal distances reached normal range at this time, 47 and 32 $\mathrm{mm}$, respectively. Similar normalization of these distances was also observed in Case 2. Mild
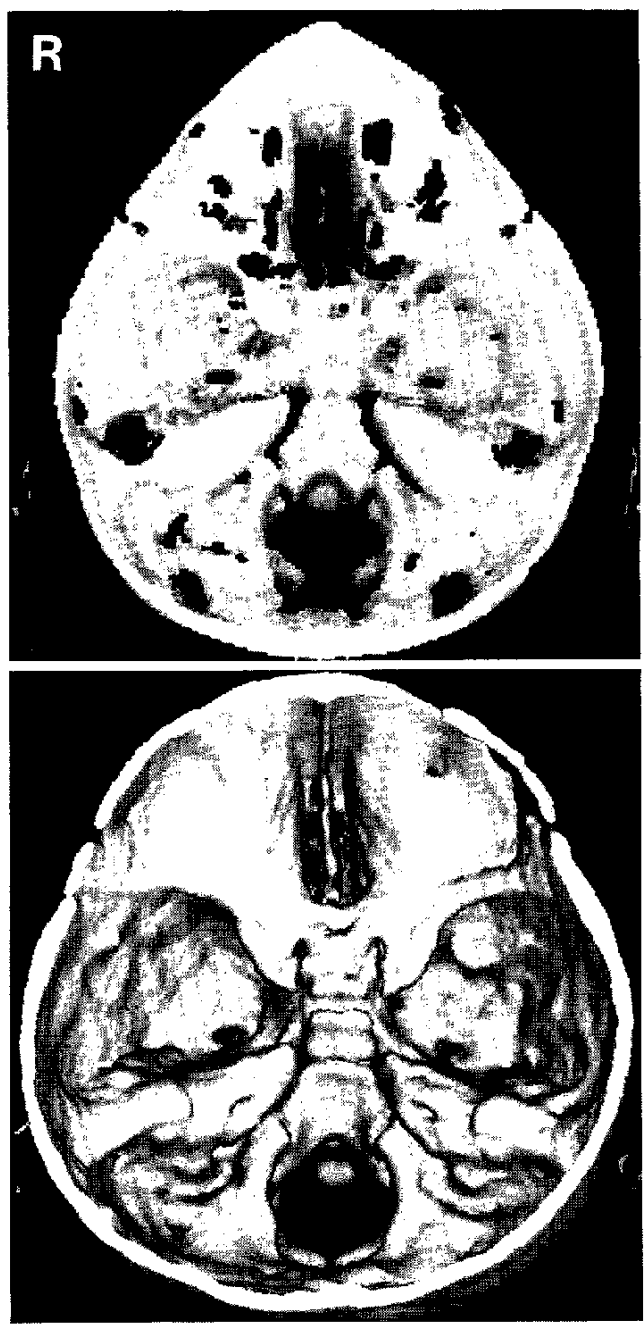

Fig. 4 Case 1. Comparison of three-dimensional osseous surface computed tomography scans of the skull base, the preoperative view (upper) showing the poorly developed anterior cranial fossa, and the postoperative view (lower) 1 year after surgery showing the good expansion of the anterior cranial fossa after surgical correction. hypotelorism persisted in Case 3 , but no patient developed additional ocular complications during the follow-up period.

The skull defects after coronal and metopic suturectomy were easily recognized after surgery. Follow-up CT and/or palpation disclosed rapid bone growth in these areas. The skull defects were completely replaced by new bone tissues during the follow-up period in Cases 1 and 2. However, the older Case 3 still had defects on the latest follow-up CT scans.

\section{Discussion}

Craniosynostoses can be divided into two main groups based on whether the anatomicofunctional lesion is centered mainly on the sagittal suture, or involves the coronal and anterior cranial base sutures. ${ }^{12)}$ In the first group, the skull base anomalies are secondary and can be corrected by early surgical treatment of the vault deformity. Metopic synostosis as well as coronal synostosis and other complex craniofaciostenosis belong to the second group, which can be defined as anterior craniosynostoses, because of the constant involvement of the coronal and anterior cranial base sutures..$^{1,12,19,22,27-30)}$

In patients with anterior craniosynostoses, the skull fails to expand at the level of the anatomicofunctional ring formed by the continuation of the coronal, sphenoethmoidal, frontosphenoidal, and frontoethmoidal sutures, resulting in narrowing of the anterior cranial fossa and the orbits very early in life. ${ }^{12,17,21)}$ Therefore, the conventional surgical treatment for trigonocephaly, strip craniotomy, has yielded inconsistent results. ${ }^{2-4,15,24)}$ Surgical treatment for patients with trigonocephaly should not be limited to opening of the prematurely fused metopic suture and removal of the wedge-shaped forehead, but should also be extended to the cranial base to achieve an immediate increase in volume of the anterior cranial fossa. Advancement of the supraorbital ridge is an essential step, and overcomes the limits of previous procedures. ${ }^{12,21-23,28)}$

Placement of buttress grafts is an important step to maintain the supraorbital ridge in the appropriate position. The shape of the grafts requires special attention. ${ }^{20-23)}$ Adequately curved bone plates obtained from the coronal suturectomy are chosen and the bone edges are elaborately trimmed for better adaptation. Bone plates involving coronal sutures might be advantageous for rapid bone growth. We believe that these small artifices promote rapid and flawless bony fusion, and will result in natural contours of the pterional region. 
Premature fusion of the frontoethmoidal suture in trigonocephalic patients is considered to be responsible for the development of midface hypoplasia such as hypotelorism. ${ }^{9]}$ Whether the surgery restricted to the forehead and the supraorbital bar is adequate for the correction of hypotelorism is still controversial. ${ }^{7,13,16)}$ More extended procedures to directly increase interorbital distances have been recommended. ${ }^{6,17,25,26]}$ However, we believe that the combination of lateral canthal advancement and radical forehead remodeling including dissection of the anterior part of the frontoethmoidal suture will prevent the development of midface hypoplasia such as hypotelorism. The rapid normalization of intercanthal and interpupillary distances observed in our patients supports this assumption. Since the majority of intercanthal growth occurs in the first 6 months of life in normal children, surgery should be carried out during this period. ${ }^{16]}$

Many craniofacial anomalies are accompanied by abnormal extraocular motility due to the abnormal anatomy of the orbit. A recent ophthalmological study indicated that patients with trigonocephaly are at risk of developing astigmatism and sometimes strabismus. ${ }^{11)}$ Such ocular abnormalities become more frequent and pronounced in older children. Binocular vision is fully developed by approximately 6 months of age, so corrective surgery should be carried out before this deadline to avoid these ocular complications. ${ }^{7111}$

The growth and the final shape of the skull after surgery is determined by the growth of the brain. The human brain grows more rapidly during the first 6 months than during the remainder of childhood., ${ }^{4,9,12,21,24)}$ In addition, skull growth in the resultant bony defects might be more rapid and complete in younger patients than in older ones. ${ }^{7]}$ Therefore, 3-6 months is probably the optimal age for surgery. This timing balances the opportunities for favorable results in younger infants with the lower perioperative risks and the reduced probability of blood transfusion in older infants.

\section{References}

1) Albright AL, Byrd RP: Suture pathology in craniosynostosis. J Neurosurg 54: 384-387, 1981

2) Anderson FM: Treatment of coronal and metopic synostosis: 107 cases. Neurosurgery 8: 143-149, 1981

3) Anderson FM, Geiger L: Craniosynostosis: A survey of 204 cases. J Neurosurg 22: 229-240, 1965

4) Anderson FM, Gwinn JL, Todt JC: Trigonocephaly: Identification and surgical treatment. J Neurosurg 19: 723-730, 1962

5) Bixler D, Ward RE: Craniosynostosis, in Myrianthopoulos NC (ed): Handbook of Clinical Neurology, vol 6 (50). Amsterdam, Elsevier Science Publishers, 1987, pp 113-128

6) Cohen SR, Kawamoto HK, Burstein F, Peacock WJ: Advancement-onlay: An improved technique of fronto-orbital remodeling in craniosynostosis. Childs Nerv Syst 7: 264-271, 1991

7) Collmann H, Sorensen N, Krauss J: Consensus: Trigonocephaly. Childs Nerv Syst 12: 664-668, 1996

8) Currarino G, Silverman FN: Orbital hypotelorism, arhinencephaly, and trigonocephaly. Radiology 74: 206-217, 1960

9) Delashaw JB, Persing JA, Park TS, Jane JA: Surgical approaches for the correction of metopic synostosis. Neurosurgery 19: 228-234, 1986

10) Demyer W: The median cleft face syndrome. Neurology 17: 961-971, 1967

11) Denis D, Genitori L, Conrath J, Lena G, Choux M: Ocular findings in children operated on for plagiocephaly and trigonocephaly. Childs Nerv Syst 12: 683-689, 1996

12) Di Rocco C: Surgical management of craniosynostosis and craniofacial deformities, in Schmidek HH, Sweet WH (eds): Operative Neurosurgical Techniques, ed 3, vol 1. Philadelphia, WB Saunders, 1996, pp 135148

13) Di Rocco C, Valardi F, Ferrario A, Marchese E: Metopic synostosis: in favor of a "simplified" surgical treatment. Childs Nerv Syst 12: 654-663, 1996

14) Dominguez R, Sang $K$, Bender T, Girdany BR: Uncomplicated trigonocephaly. A radiographic affirmation of conservative therapy. Radiology 140: 681-688, 1981

15) Ehni G: Cranioplasty for premature metopic suture closure (trigonocephaly). Acta Neurochir (Wien) 61: 201-206, 1982

16) Fearon JA, Kolar JC, Munro IR: Trigonocephaly-associated hypotelorism: Is treatment necessary? Plast Reconstr Surg 97: 503-511, 1996

17) Friede $\mathrm{H}$, Alberius P, Lilja J, Lauritzen C: Trigonocephaly: Clinical and cephalometric assessment of craniofacial morphology in operated and nonoperated patients. Cleft Palate J 27: 362-367, 1990

18) Goodman RM, Gorlin RJ: The Malformed Infant and Child. An Illustrated Guide. New York, Oxford University Press, 1983, pp 432-435

19) Haaf T, Hofmann R, Schmid M: Opitz trigonocephaly syndrome. Am J Med Genet 40: 444-446, 1991

20) Hoffman HJ: Procedure of lateral canthal advancement for the treatment of coronal synostosis. Childs Nerv Syst 12: 678-682, 1996

21) Hoffman HJ, Hendrick EB: Early neurosurgical repair in craniofacial dysmorphism. J Neurosurg 51: 796-803, 1979

22) Marchac D: Radical forehead remodeling for craniostenosis. Plast Reconstr Surg 61: 823-835, 1978

23) Marsh JL, Schwartz HG: The surgical correction of coronal and metopic craniosynostoses. J Neurosurg 59: 245-251, 1983

24) Matson DD: Surgical treatment of congenital anomalies of the coronal and metopic sutures. Technical 
note. J Neurosurg 17: 413-417, 1960

25) McCarthy JG, Bradley JP, Longaker MT: Step expansion of the frontal bar: correction of trigonocephaly. J Cardiovasc Surg 7: 333-335, 1996

26) Mommaerts MY, Staels P: Coronal suture transposition to correct fronto-orbital constriction in metopic synostosis. Int Surg 81: 210-214, 1996

27) Moss ML: Functional anatomy of cranial synostosis. Childs Brain 1: 22-33, 1975

28) Oi S, Matsumoto S: [Early radical operation for trigonocephaly in infancy. Pathophysiological concepts for and operative procedure of premature closure of metopic suture]. No Shinkei Geka 14: 10871092, 1986 (Jpn, with Eng abstract)

29) Seeger JF, Gabrielsen TO: Premature closure of the frontosphenoidal suture in synostosis of the coronal suture. Radiology 101: 631-635, 1971

30) Tessier P: Relationship of craniostenoses to craniofacial dysostoses, and to faciostenoses. A study with therapeutic implications. Plast Reconstr Surg 48: 224-237, 1971

31) Winston KR: Craniosynostosis, in Wilkins RH, Rengachary SS (eds): Neurosurgery, ed 2, vol 3. New York, McGraw-Hill Health Professing Division, 1996, pp 3673-3692

Address reprint requests to: E. Moriyama, M.D., Department of Neurosurgery, Fukuyama National Hospital, 4-14-17 Okinogami-cho, Fukuyama, Hiroshima 720-0825, Japan.

\section{Commentary}

With the most recent advances in three-dimensional CT (3-D CT), it has become possible to clearly visualize the facial and cranial dysmorphism of patients with craniosynostosis. 3-D CT technology is extremely beneficial in displaying real images of the postoperative course. In this paper, the authors describe clearly and in detail their operative methodology which involves the frontotemporal cranial base for trigonocephaly. It is commonly thought that a rigid fixation of the bone flap with craniotomy is not necessary for patients under 6 months old but should be per- formed in the case of older patients. Also, as stated in this paper, in the case of the 8-year-old patient (Case 3) the compensatory bone formation was extremely delayed because of cranioplasty to correct heavy bone defects. However, it is obvious that satisfactory surgical results were obtained by this extensive cranial correction involving the cranial base with bilateral canthal advancement. It is interesting to consider the pathophysiology of this disease. It seems that the correction of calvarial deformities should be accompanied by cranial base corrections to achieve maximum results.

Takashi HAYASHI, M.D. Department of Neurosurgery

St. Mary's Hospital Fukuoka, Japan

Technical aspects of surgical treatment for trigonocephaly are discussed on the basis of the authors' experiences of 3 cases. Surgical procedures are described in detail for one of 3 patients who successfully underwent surgical correction by lateral canthal advancement, a technique that is now widely used and is one of the standard surgical treatments for craniostenosis. Diagrams of the operative technique are well presented and instructive, together with excellent preoperative and postoperative 3D-CT scans. However, most of the descriptions are similar to those reported by other authors. The authors' own innovative technical procedures need to be clearly defined, in comparison with those of Hoffman and Hendrick (ref. 21 of this article) or Marsh and Schwartz (ref. 23). The 3rd case, i.e. the older patient, should have been presented in more detail with emphasis on the postoperative skull defect and remaining hypotelorism. Assessment of hypotelorism should have used normal values for the Japanese population, and not those for Europeans.

Kouzo MoRtTaKe, M.D. Department of Neurosurgery Shimane Medical University Shimane, Japan 